\title{
Electrochemical Behaviors and Sensitive Determination of Guanosine-5'-monophosphate on Ionic Liquid Modified Carbon Paste Electrode
}

\author{
Wei Sun, ${ }^{\mathrm{a}, *}$ Li Xu, ${ }^{\mathrm{b}}$ Jun Liu, ${ }^{\mathrm{b}}$ Xiuzhen Wang, ${ }^{\mathrm{b}}$ Song Hu, ${ }^{\mathrm{c}, *}$ and Jun Xiang ${ }^{\mathrm{c}}$ \\ ${ }^{a}$ College of Chemistry and Chemical Engineering, Hainan Normal University, Haikou 571158, P. R. China \\ ${ }^{\mathrm{b}}$ College of Chemistry and Molecular Engineering, Qingdao University of Science and Technology, \\ Qingdao 266042, P. R. China \\ ${ }^{\mathrm{c}}$ State Key Laboratory of Coal Combustion, Huazhong University of Science and Technology, \\ Wuhan 430074, P. R. China
}

RECEIVED AUGUST 8, 2011; REVISED APRIL 20, 2012; ACCEPTED AUGUST 27, 2012

\begin{abstract}
A new electrochemical sensor was fabricated by using ionic liquid (IL) 1-octyl-3-methylimidazolium hexafluorophosphate $\left(\mathrm{OMIMPF}_{6}\right)$ modified carbon paste electrode (denoted as IL-CPE). The electrode was characterized by scanning electron microscopy, cyclic voltammetry and electrochemical impedance spectroscopy. Due to the presence of high conductive IL in the carbon paste electrode, IL-CPE exhibited excellent electrocatalytic ability to the oxidation of guanosine-5'-monophosphate (GMP) with the increase of the oxidation peak current. A single well-defined irreversible oxidation peak appeared at $+1.14 \mathrm{~V}$ in a B-R buffer of $\mathrm{pH}=5.0$ with adsorption-controlled process. The electrochemical reaction parameters of GMP oxidation were calculated with the electron transfer coefficient $(\alpha)$ as 0.32 , the apparent heterogeneous electron transfer rate constant, $k_{\mathrm{s}}=9.14 \times 10^{-5} \mathrm{~s}^{-1}$ and the surface coverage, $\Gamma_{\mathrm{T}}=2.34 \times 10^{-9}$ $\mathrm{mol} \mathrm{cm}{ }^{-2}$. Under the selected conditions the oxidation peak current was proportional to GMP concentration over the range from 1.0 to $1000.0 \mu \mathrm{mol} \mathrm{dm}{ }^{-3}$ with the detection limit as $0.16 \mu \mathrm{mol} \mathrm{dm}{ }^{-3}(3 \sigma)$ by differential pulse voltammetry. The proposed method was further applied to determine the GMP contents in artificial samples and chicken powder samples with satisfactory results. (doi: 10.5562/cca1976)
\end{abstract}

Keywords: carbon ionic liquid electrode, guanosine-5'-monophosphate, cyclic voltammetry, differential pulse voltammetry, 1-octyl-3-methylimidazolium hexafluorophosphate

\section{INTRODUCTION}

Guanine nucleotides serve as energy sources ${ }^{1}$ and play an important role in regulatory systems in a wide variety of tissues and organisms, which can facilitate the maintenance of the internal milieu. ${ }^{2}$ Guanosine-5'-monophosphate (GMP) is one of the four main ribosyl nucleotides present in RNA, which can be synthesized in the human body and plays a crucial role in many functions related to normal cellular metabolism and cardiac activities, such as enhancing the immune response, influencing the metabolism of fatty acids and improving the gastrointestinal tract repair after damage, ${ }^{3}$ exerting trophic effects on neural cells, ${ }^{4,5}$ protecting brain slices in a model of hypoxia, ${ }^{6}$ stimulating the removal of extracellular glutamate by astrocytes ${ }^{7,8}$ and so on. Therefore, it is necessary to establish a sensitive and reliable method for GMP determination. Up to now different kinds of analytical methods such as as luminescence method, ${ }^{9}$ high performance liquid chromatography (HPLC),${ }^{10}$ ion-pair HPLC, ${ }^{11}$ capillary zone electrophoresis $^{12}$ and electrochemical methods ${ }^{13,14}$ had been developed for the sensitive determination of GMP. Some of these methods require expensive instruments with time consuming. Electrochemical methods have been proven to be an efficient way for the determination of GMP with the advantages such as high sensitivity, simplicity, low cost and excellent selectivity, small dimensional and cheap instruments. Rajendra et al. investigated the electrooxidation of GMP at the pyrolytic graphite electrode. ${ }^{15} \mathrm{Xie}$ et al. also investigated the electrocatalytic oxidation of GMP on a redox polymer film modified indium tin oxide (ITO) electrode. ${ }^{16}$ All the results indicated that electrochemical oxidation of GMP could be realized and greatly enhanced on the modified electrodes.

In recent years ionic liquid (IL) has been used as a new kind of binder in the carbon paste electrode (CPE) to fabricate an IL modified electrode, which exhibits as

\footnotetext{
* Authors to whom correspondence should be addressed. (E-mails: swyy26@hotmail.com and hssh30@163.com)
} 
high performance working electrode in the field of electrochemical sensor. ${ }^{17-19}$ ILs exhibit the specific characteristics such as good chemical and thermal stability, almost negligible vapor pressure, good ionic conductivity and wide electrochemical windows, which have been widely used in different fields of electrochemistry. ${ }^{20,21}$ Maleki et al. indicated that IL modified CPE exhibited the superiority to different kinds of carbon electrodes such as glassy carbon electrode (GCE), carbon nanotubes (CNTs) modified electrode and edge plane pyrolytic graphite electrode. ${ }^{22}$ IL-CPE exhibits many advantages such as high electrocatalytic activity, wide electrochemical windows and good antifouling ability, so it is used for the electroanalytical chemistry or electrochemical biosensors. Zhang et al. applied a 1-amyl3-methylimidazolium bromide modified CPE for the sensitive voltammetric determination of rutin. ${ }^{23}$ Our groups also applied different kinds of IL-CPE to study the direct electrochemistry of electroactive substances such as hemoglobin ( $\mathrm{Hb})$, ssDNA, dsDNA, catechol and so on. ${ }^{24-28}$

In this study an IL 1-octyl-3-methylimidazolium hexafluorophosphate $\left(\mathrm{OMIMPF}_{6}\right)$ modified electrode was used for the electrochemical determination of GMP for the first time. The selected $\mathrm{OMIMPF}_{6}$ was a hydrophobic IL that was more efficient for ion transfer within the CPE than other polar liquid. ${ }^{29}$ Optimal conditions for the electrochemical analysis were selected and GMP exhibited an adsorption controlled electrochemical process on IL-CPE. The electrochemical parameters of GMP were calculated and the prepared electrode showed high sensitivity and stability with the GMP determination over the concentration range from 1.0 to $1000.0 \mu \mathrm{mol} \mathrm{dm}{ }^{-3}$.

\section{EXPERIMENTAL}

\section{Reagents}

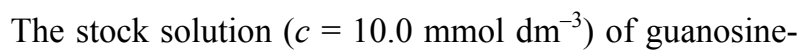
5'-monophosphate (GMP, $\geq 98.0 \%$, Shanghai Kayon Biological Tech. Ltd. Co., China) was prepared just before use and stored in a refrigerator at $4{ }^{\circ} \mathrm{C}$. IL 1-octyl3-methylimidazolium hexafluorophosphate $\left(\mathrm{OMIMPF}_{6}\right.$, Hangzhou Kemer Chemical Ltd. Co., China), graphite powder (average particle size $30 \mu \mathrm{m}$, Shanghai Colloid Chemical Co., China) and adenosine-5'-triphosphate (ATP, $\geq 98.0 \%$, Shanghai Kayon Biological Technology Ltd. Co., China) were used without furthur purification. $0.2 \mathrm{M}$ Britton-Robinson (B-R) buffer solutions with various $\mathrm{pH}$ values were used as the supporting electrolyte. All the solutions were prepared from double-distilled water and other chemicals used were of analytical reagent grade.

\section{Apparatus}

All the voltammetric measurements were carried out on a CHI 1210A electrochemical workstation (Shanghai $\mathrm{CH}$ Instruments, China). A three-electrode system, which was composed of a IL-CPE as working electrode, a saturated calomel electrode (SCE) as reference electrode and a platinum wire as auxiliary electrode, was employed in the experiment. Electrochemical impedance spectroscopy (EIS) was performed on a CHI 750B electrochemical workstation (Shanghai CH Instruments, China). Scanning electron microscopy (SEM) was conducted with a JSM-6700F scanning electron microscope (Japan Electron Company, Japan).

\section{Fabrication of Modified Electrodes}

The traditional CPE was prepared by hand-mixing of graphite powder with liquid paraffin at a mass ratio of 70:30 in an agate mortar. The $\mathrm{OMIMPF}_{6}$ modified CPE was fabricated by mixing $0.25 \mathrm{~g}$ of $\mathrm{OMIMPF}_{6}, 3.2 \mathrm{~g}$ of graphite powder and $1.0 \mathrm{~mL}$ of liquid paraffin in a mortar. The homogeneous paste was packed into a cavity of glass tube with the diameter of $4.2 \mathrm{~mm}$. The electrical contact was got with a copper wire connected to the paste in the tube and the surfaces of CPE or IL-CPE were polished on a weighing paper just before use.

\section{Voltammetric Measurements}

The three-electrode system was immersed in a $10 \mathrm{~mL}$ electrochemical cell with proper amount of GMP and $0.2 \mathrm{M} \mathrm{B}-\mathrm{R}$ buffer solution $(\mathrm{pH}=5.0)$. After accumulation at $0.3 \mathrm{~V}$ in a still solution for $60 \mathrm{~s}$, cyclic voltammetric experiments were performed in the potential range from 0.8 to $1.6 \mathrm{~V}$ with the scan rate as $100 \mathrm{mV}$ $\mathrm{s}^{-1}$. The experimental parameters of differential pulse voltammetry (DPV) were selected as follow: increment potential, $0.008 \mathrm{~V}$; pulse amplitude, $0.05 \mathrm{~V}$; pulse width, $0.05 \mathrm{~s}$; sample width, $0.0167 \mathrm{~s}$; pulse period, $0.2 \mathrm{~s}$; quiet time, $30 \mathrm{~s}$. The voltammograms of B-R buffer solution were recorded and used as the background.

\section{RESULTS AND DISCUSSION}

\section{Characteristics of the IL Modified Electrode}

Figure 1a showed the SEM image of CPE and the surface was not very smooth. On the IL-CPE a more uniform surface topography was obtained with graphite particles dispersed and bridged by $\mathrm{OMIMPF}_{6}$ (Figure $1 b$ ), which was related to the preparation process of the modified carbon paste. $\mathrm{OMIMPF}_{6}$ is an IL with high viscosity, which can disperse and adhere the graphite powder together with void space filled with IL, so the uniform surface appeared on IL-CPE. 
Ferricyanide/ferrocyanide redox system is used to compare the electroactivity of the modified electrodes. Cyclic voltammograms of CPE and IL-CPE were recorded in a $0.5 \mathrm{M} \mathrm{KCl}$ solution containing $\mathrm{K}_{3}\left[\mathrm{Fe}(\mathrm{CN})_{6}\right]$ $\left(c=1.0 \mathrm{mmol} \mathrm{dm}{ }^{-3}\right)$ at a scan rate of $100 \mathrm{mV} \mathrm{s}^{-1}$. As shown in Figure 1c, the redox peak current of $\left[\mathrm{Fe}(\mathrm{CN})_{6}\right]^{3-/ 4-}$ probe were much higher at IL-CPE with the peak-to-peak separation, $\Delta E=90 \mathrm{mV}$ (curve b) as compared to that of $\mathrm{CPE}$, which had the value of $\Delta E=$ $382 \mathrm{mV}$ (curve 1). This result informed that IL-CPE could provide an increased electrochemical response and better reversibility due to the good ionic conductivity of IL in the carbon paste. The faradic current $\left(I_{\mathrm{p}}\right)$ of ferricyanide exhibited good linear relationship with the square root of scan rate $\left(v^{1 / 2}\right)$ in the range from 30.0 to $500.0 \mathrm{mV} \mathrm{s}^{-1}$, indicating the electrode process was controlled by a semi-infinite linear diffusional process. The electrochemical effective area of IL-CPE was estimated by the Randles-Sevcik equation using ferricyanide $(c=$ $1.0 \mathrm{mmol} \mathrm{dm}^{-3}$ as the electrochemical probe. By exploring the relationship of $I_{\mathrm{p}}$ with scan rate, an electrochemical effective area of $0.15 \mathrm{~cm}^{2}$ was obtained for IL-CPE, while the electrochemical area of $\mathrm{CPE}$, though with same geometric area, was only $0.11 \mathrm{~cm}^{2}$.

The interfacial properties of the modified electrodes were furthur compared by electrochemical impedance spectroscopy (EIS) with the typical Nyquist plots presented in Figure 1d. EIS is a commonly used method to probe the interface information during the modification process of the chemically modified electrodes. In EIS results the semicircular part at higher frequencies corresponds to the electron transfer limited process and the linear part at lower frequencies corresponds to the diffusion process. The diameter of the semicircle is equal to the electron transfer resistance (Ret), which controls the electron transfer kinetics of the redox probe at the electrode interface. In Figure 1d the $Z^{\prime}$ and $Z^{\prime \prime}$ are the real and imaginary variable of impedance and the Randle circuit (Figure 1d, inset) is further used to fit the impedance data obtained in the experiment. Here the semi-circular part at higher frequencies corresponds to the electron-transfer limited process, and its diameter is equal to the electron-transfer resistance (Ret), which controls the electron-transfer kinetics of the redox probe at the electrode interface. On traditional CPE a big semicircle domain appeared, indicating a high electron transfer resistance existed (curve 1). The result was due to the nonconductive liquid paraffin existed in the carbon paste. While on IL-CPE a nearly straight line appeared (curve 2) and the Ret value of IL-CPE (47.47 $\Omega$ ) was much smaller than that of CPE (1035.95 $\Omega$ ), also indicating the loading of high ionic conductive ILs into carbon paste improved the conductivity of the modified electrode.
The capacitance of the modified electrode was further calculated from the experimental background current by using the equation of $C^{\text {app }}=I /(S \cdot v),{ }^{30}$ where $I$ is the average of the positive and the negative charging current obtained from the cyclic voltammetric curves at $0.4 \mathrm{~V}$, which were performed in phosphate buffer solution $\left(c=0.05 \mathrm{~mol} \mathrm{dm}^{-3}, \mathrm{pH}=7.4\right)$ between 0 and $0.6 \mathrm{~V} ; S$ is the geometric area of the electrode; $v$ is the scan rate. The capacitance value of IL-CPE was calculated as $46.11 \mu \mathrm{F} \mathrm{cm}$, which was much higher than that of the CPE (6.1 $\mu \mathrm{F} \mathrm{cm}{ }^{-2}$ ). The increase of the capacitance of the modified electrode reflected that the presence of IL film on the electrode surface could act as the double layer on the interface.

The optimal amount of IL added in CPE was selected to get the best stability and electrochemical response. By changing the ratio of IL with liquid paraffin in the carbon paste and the electrochemical responses of modified electrodes were recorded in the ferricyanide solution and compared, a final amount of $0.25 \mathrm{~g} \mathrm{OMIMPF}_{6}$ was selected for the preparation of IL-CPE, which gave the smallest $\Delta E$ value and the highest redox peak current. The electrochemical response did not changed after scanning in the ferricyanide solution for 50 circles at the scan rate of $100 \mathrm{mV} \mathrm{s}^{-1}$, indicating the good stability of IL-CPE at the selected preparation ratio.
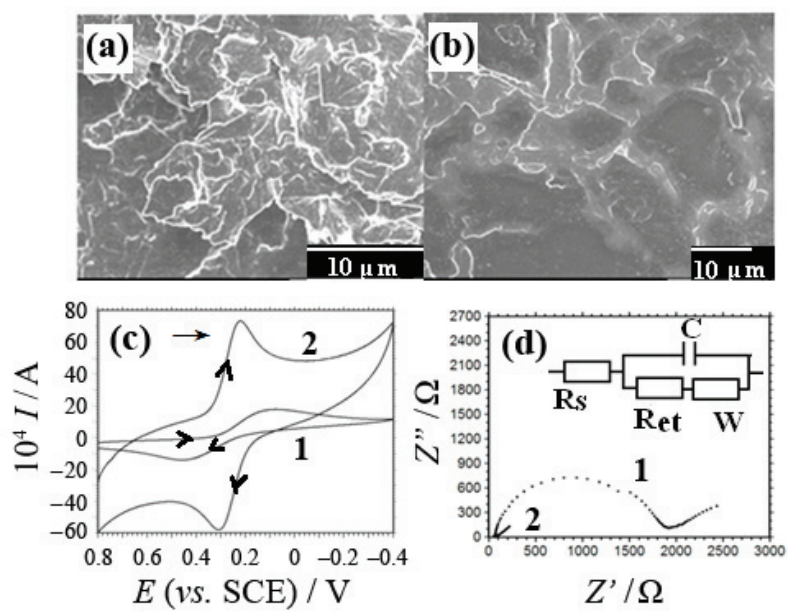

Figure 1. SEM images of CPE (a) and IL-CPE (b); Cyclic voltamograms (c) of CPE (1) and IL-CPE (2) in a solution of $0.5 \mathrm{M} \mathrm{KCl}$ containing $1.0 \mathrm{mmol} \mathrm{dm}^{-3} \mathrm{~K}_{3}\left[\mathrm{Fe}(\mathrm{CN})_{6}\right]$ at the scan rate of $100 \mathrm{mV} \mathrm{s}^{-1}$; Electrochemical impedance spectra (d) for CPE (1) and IL-CPE (2) in a solution of $0.1 \mathrm{M} \mathrm{KCl}$ containing $0.1 \mathrm{mmol} \mathrm{dm}^{-3}\left[\mathrm{Fe}(\mathrm{CN})_{6}\right]^{3-/ 4-}$ and with the frequencies swept from $10^{5}$ to $10^{-2} \mathrm{~Hz}$. 


\section{Cyclic Voltamogram of GMP}

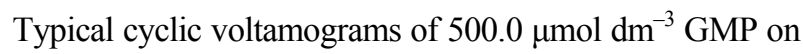
IL-CPE and CPE were recorded and shown in Figure 2. No voltammetric responses appeared on IL-CPE (curve a) and CPE (curve c) in B-R buffer solution $(\mathrm{pH}=5.0$ ), indicating no electrochemical reaction took place. The oxidation peak potential of GMP appeared at $+1.15 \mathrm{~V}$ on CPE (curve d) and at $+1.14 \mathrm{~V}$ on IL-CPE (curve b) without any reduction peak, which indicated a totally irreversible electrode process under the selected conditions. At the same time, the oxidation peak current of GMP on IL-CPE was 1.85 times larger than that of CPE. The results indicated that IL-CPE exhibited an electrocatalytic activity toward the GMP oxidation. Based on the reference ${ }^{29}$ IL-CPE showed an enhanced electrochemical performance than CPE due to the presence of IL in the carbon paste, which could not only facilitate the electron transfer rate between GMP and electrode, but also accumulate more GMP on the electrode surface due to the presence of IL film. So the improved determination sensitivity was achieved on IL-CPE.

\section{Effect of Buffer pH}

The effect of solution $\mathrm{pH}$ on the oxidation response of GMP was investigated by cyclic voltammetry in the $\mathrm{pH}$ range of 3.5-8.0. In the $\mathrm{pH}$ range investigated a stable and well-defined irreversible oxidation peak was obtained and the relationship of the electrochemical responses with $\mathrm{pH}$ value was plotted with the results shown in Figure 3. The highest oxidation peak current was observed at $\mathrm{pH}=5.0$ and then decreased with increasing $\mathrm{pH}$. Therefore buffer of $\mathrm{pH}=5.0$ was selected as the optimal supporting electrolyte solution. The oxidation peak potential $\left(E_{\mathrm{pa}}\right)$ shifted to the negative direction with the increase of solution $\mathrm{pH}$ value, indicating

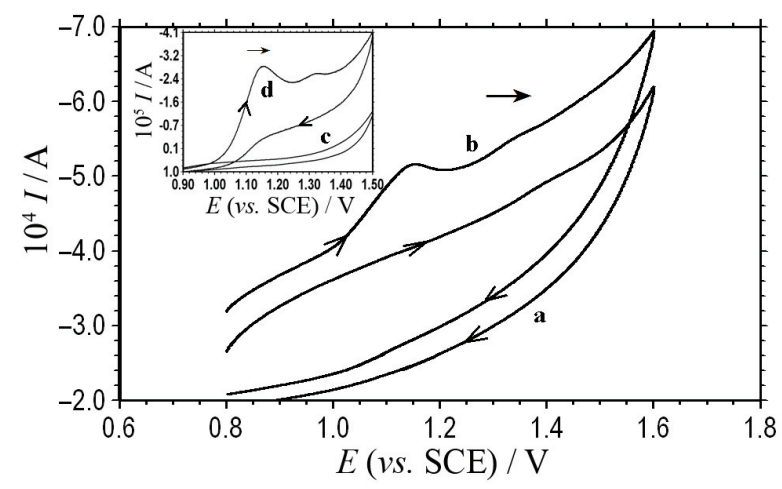

Figure 2. Cyclic voltamograms of IL-CPE (a), CPE in Britton-Robinson buffer solution of $\mathrm{pH}=5.0$ and that of 500.0 $\mu \mathrm{mol} \mathrm{dm}{ }^{-3}$ GMP (c) on IL-CPE (b), CPE (d), respectively. Conditions: preconcentration at $+0.30 \mathrm{~V}$ for $60 \mathrm{~s}$ with the scan rate as $100 \mathrm{mV} \mathrm{s}^{-1}$. that protons took part in the electrode reaction. The relationship between the oxidation peak potential and buffer $\mathrm{pH}$ was investigated with the linear regression equation as $E_{\mathrm{pa}} / \mathrm{V}=-0.051 \mathrm{pH}+1.410(\gamma=0.996)$. The slope value of $-51 \mathrm{mV} \mathrm{pH}^{-1}$ was close to the theoretical Nernst response of $-59 \mathrm{mV} \mathrm{pH}^{-1}$, indicating that equal numbers of protons and electrons were involved in electrochemical oxidation of GMP.

\section{Effect of Scan Rate}

The influence of scan rate on the oxidation peak current of GMP was investigated in the range from 30 to 500 $\mathrm{mV} \mathrm{s}^{-1}$. With the increase of scan rate the oxidation peak current increased gradually and a linear relationship was got between the oxidation peak current $\left(I_{\mathrm{pa}}\right)$ and scan rate $(v)$ with the linear regression equation as $I_{\mathrm{pa}} / \mu \mathrm{A}=-335.26 v / \mathrm{V} \mathrm{s}^{-1}-22.26(\gamma=0.999)$, indicating an surface-confined adsorption-controlled electrode process. According to the following equation:

$$
I_{\mathrm{p}}=\frac{n F Q v}{4 R T}=\frac{n^{2} F^{2} A \Gamma_{T} v}{4 R T}
$$

where $A$ is the effective area of the electrode; $Q$ is the charge involved in the reaction; $v$ is scan rate; $\Gamma_{\mathrm{T}}$ is the amount of the adsorbed analyte, $n, R, F$ and $T$ have their common meanings. The coverage concentration $\left(\Gamma_{\mathrm{T}}\right)$ of GMP on the electrode surface can be calculated as $2.34 \times 10^{-9} \mathrm{~mol} \mathrm{~cm}^{-2}$ from the slope of the plot of $I_{\mathrm{pa}} v s . v$. With the increase of scan rate the oxidation peak potential moved to a positive direction and the oxidation peak potential $\left(E_{\mathrm{pa}}\right)$ was proportional to the logarithm of scan rate with the equation as $E_{\mathrm{pa}} / \mathrm{V}=0.037 \ln v / \mathrm{Vs}^{-1}+1.21(\gamma=0.997)$. Based on the Laviron's equations: ${ }^{31}$

$$
E_{\mathrm{pa}}=E^{0^{\prime}}+\frac{R T}{(1-\alpha) n F} \ln v
$$

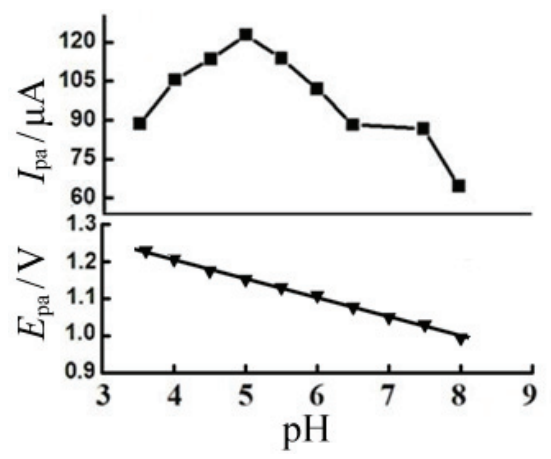

Figure 3. The relationship of the oxidation peak current $\left(I_{\mathrm{pa}}\right)$ and the oxidation peak potential $\left(E_{\mathrm{pa}}\right)$ with buffer $\mathrm{pH}$. Conditions: preconcentration at $+0.30 \mathrm{~V}$ for $60 \mathrm{~s}$ with the scan rate as $100 \mathrm{mV} \mathrm{s}^{-1}$. 

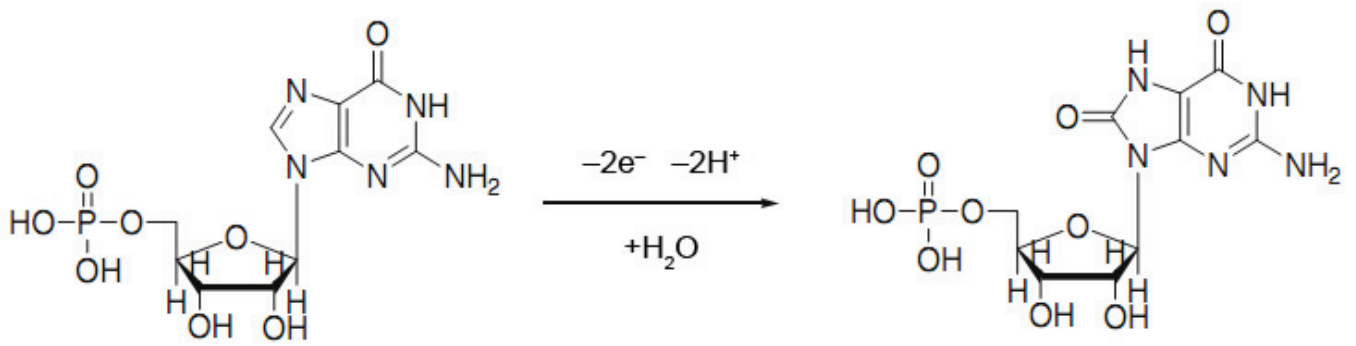

Scheme 1. Electro-oxidation process of GMP

$$
\begin{gathered}
\log k_{\mathrm{s}}=\alpha \log (1-\alpha)+(1-\alpha) \\
\log \alpha-\log \frac{R T}{n F v}-\frac{(1-\alpha) \alpha n F \Delta E_{\mathrm{p}}}{2.3 R T}
\end{gathered}
$$

The values of the charge transfer coefficient $(\alpha)$ and electrode reaction standard rate constant $\left(k_{\mathrm{s}}\right)$ were calculated to be 0.32 and $9.14 \times 10^{-5} \mathrm{~s}^{-1}$, respectively.

Based on the above results, an electrooxidation mechanism of GMP can be proposed in Scheme 1, which involved in the oxidation of GMP molecules to form 8-oxoguanine occuring in the nucleophilic $\mathrm{N}(7)=\mathrm{C}(8)-$ bond of guanine base. ${ }^{32}$

\section{Optimal Experimental Conditions}

Due to the adsorption process of GMP on IL-CPE, accumulation step can increase the concentration of GMP on the electrode surface, and then enhance the sensitivity. The effect of accumulation potential was tested from $0.3 \mathrm{~V}$ to $0.8 \mathrm{~V}$ and the oxidation peak current of GMP had no change, implying that the accumulation process was almost independent of electrostatic interaction. Hence $0.3 \mathrm{~V}$ was chosen as the accumulation potential. The oxidation peak current of GMP $(c=$ $500.0 \mu \mathrm{mol} \mathrm{dm}{ }^{-3}$ ) increased with the increase of accumulation time in the range from 0 to $60 \mathrm{~s}$. When the accumulation time was above $60 \mathrm{~s}$, the peak current increased little and kept almost unchanged, which indicated the saturated adsorption of GMP on the electrode surface, so the optimal accumulation time was fixed at $60 \mathrm{~s}$ in the following experiments.

\section{Calibration Curve}

Under the selected conditions the relationship between the oxidation peak current of GMP with its concentration was established with the typical differential pulse voltammograms shown in Figure 4. The oxidation peak current increased linearly with the GMP concentration. A good linear relationship was got in the concentration

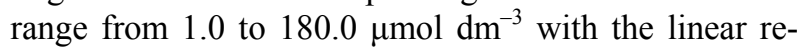
gression equation as $I_{\mathrm{pa}} / \mu \mathrm{A}=0.148 \mathrm{c} / \mu \mathrm{moldm}^{-3}+$ $1.273(\gamma=0.986)$ and in the range from 180.0 to $1000.0 \mu \mathrm{mol} \mathrm{dm}{ }^{-3}$ with the linear regression equation as $I_{\mathrm{pa}} / \mu \mathrm{A}=0.029 \mathrm{c} / \mu \mathrm{mol} \mathrm{dm}{ }^{-3}+19.874(\gamma=0.995)$. The determination limit was estimated to be $0.16 \mu \mathrm{mol} \mathrm{dm}^{-3}$ $(\mathrm{S} / \mathrm{N}=3)$, which is calculated by the equation: $c_{\mathrm{L}}=$ $K S_{\mathrm{o}} / S$, where $c_{\mathrm{L}}$ is the detection limit, $K$ is a constant related to the confidence level, according to the suggestion of IUPAC, K = 3 (99\% confidence), $S_{\mathrm{o}}$ is the standard deviation of the blank measurements $(N=9)$ and $S$ is the slope of the calibration curve. The result indicated that the proposed method could be applied to low concentration GMP determination.

Five modified electrodes were prepared by the same procedure and applied to the determination of $500.0 \mu \mathrm{mol} \mathrm{dm}{ }^{-3}$ GMP solution with the relative standard deviation (RSD) value of $3.7 \%$, which indicated that IL-CPE exhibited highly repeatability. The storage stability of IL-CPE was investigated and $96.4 \%$ of its initial current value remained after 7 days and $91.5 \%$ of the initial responses still remained after 30 days storage, indicating the good storage stability of the modified electrode.

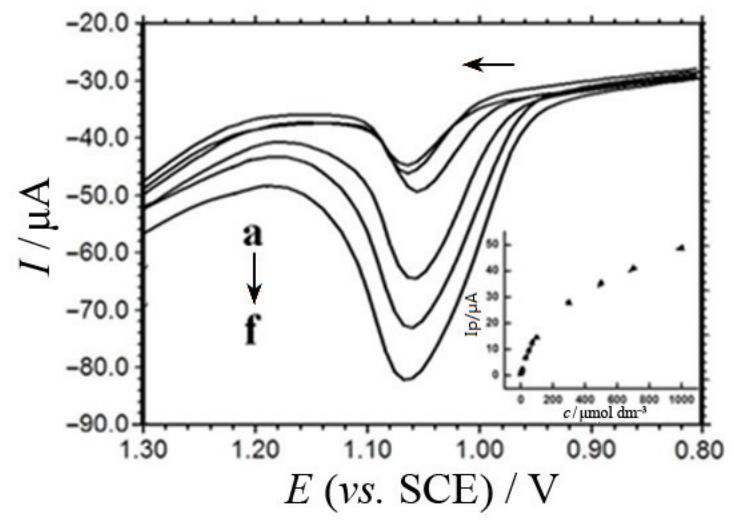

Figure 4. Differential pulse voltammograms of different GMP concentrations (from a to f: 50.0, 70.0, 100.0, 300.0, 500.0, $700.0 \mu \mathrm{mol} \mathrm{dm}^{-3}$ ) on IL-CPE in B-R buffer solution of $\mathrm{pH}=$ 5.0 at the scan rate of $100 \mathrm{mV} \mathrm{s}^{-1}$. Conditions: preconcentration at $+0.30 \mathrm{~V}$ for $60 \mathrm{~s}$. Inset was calibration curve between the oxidation peak current with GMP concentration. 
Table 1. Influence of coexisting substances on the determination of $10.0 \mu \mathrm{mol} \mathrm{dm}{ }^{-3} \mathrm{GMP}(n=3)$

\begin{tabular}{ccc}
\hline Coexisting Substance & $c / \mu \mathrm{mol} \mathrm{\textrm {dm } ^ { - 3 }}$ & Relative error $/ \%$ \\
\hline thymine & 10.0 & 3.90 \\
L-valine & 10.0 & 2.11 \\
L-thyptophan & 10.0 & 2.97 \\
L-glutamate & 10.0 & 2.18 \\
L-leucine & 10.0 & 2.51 \\
cytosine & 10.0 & 3.98 \\
$\mathrm{Mg}^{2+}$ & 10.0 & 0.27 \\
$\mathrm{Zn}^{2+}$ & 10.0 & -0.55 \\
$\mathrm{Na}^{+}$ & 10.0 & 1.12 \\
\hline
\end{tabular}

\section{Selectivity}

IL-CPE also showed excellent ability to distinguish the electrochemical responses of GMP and ATP in the mixed solution. As shown in Figure 5, cyclic voltammograms of different concentrations of GMP with a fixed concentration of ATP on IL-CPE exhibited two well-defined oxidation peaks at $1.096 \mathrm{~V}$ and 1.408 $\mathrm{V}$ (vs. SCE), respectively. The oxidation peaks were corresponded to the oxidation of GMP and ATP, respectively, with the peak-to-peak separation as $312 \mathrm{mV}$, which was large enough for the simultaneous determination. Thus, electrochemical signals of GMP and ATP were independent on IL-CPE, which exhibited good distinguish ability of the modified electrode.

The interferences of some potentially coexisting substances on the determination of $10.0 \mu \mathrm{mol} \mathrm{dm}{ }^{-3}$ GMP was systematic evaluated in B-R buffer solution of $\mathrm{pH}=5.0$. As shown in Table 1 metal ions such as $\mathrm{Na}^{+}, \mathrm{Mg}^{2+}, \mathrm{Zn}^{2+}$ and thymine, L-valine, cytosine etc. barely influenced the oxidation peak current of $10.0 \mu \mathrm{mol} \mathrm{dm}{ }^{-3}$ GMP with signal

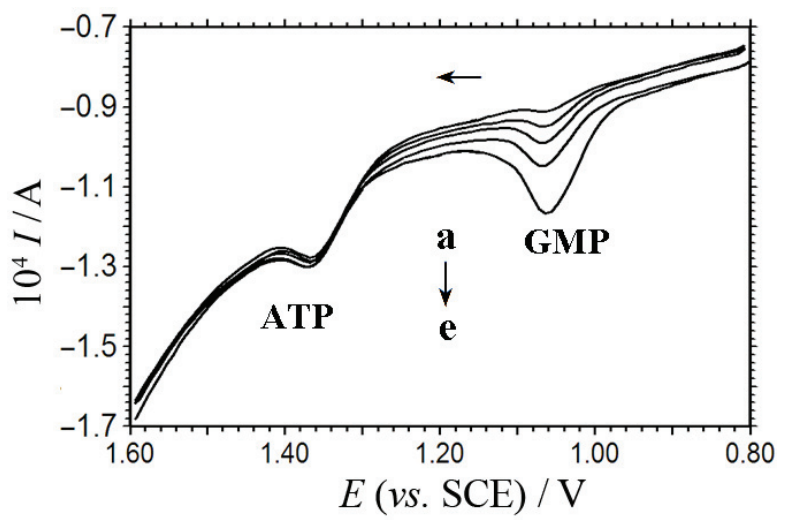

Figure 5. Differential pulse voltammograms of different concentrations of GMP on IL-CPE in B-R buffer solution of $\mathrm{pH}=5.0$ with $100.0 \mu \mathrm{mol} \mathrm{dm}{ }^{-3}$ ATP. The concentrations of GMP from a to e are 40.0, 60.0, 80.0, 100.0, $200.0 \mu \mathrm{mol} \mathrm{dm}^{-3}$.

changes below $\pm 4 \%$, revealing that IL-CPE had excellent selectivity to GMP determination.

\section{Analytical Applications}

The proposed method was applied to the determination of artificial samples, which contained several possible interferences in a biological sample, such as glycin, Lleucine, $\mathrm{Cu}^{2+}, \mathrm{Zn}^{2+}$ and $\mathrm{Na}^{+}$. Each sample was prepared by mixing $10.0 \mu \mathrm{mol} \mathrm{dm}{ }^{-3}$ interferences with different concentrations of GMP. Three samples were further detected by the experimental procedure with standard addition method. From Table 2 it can be seen that the determination results were satisfactory with the recovery in the range from $94.25 \%$ to $101.5 \%$, which indicated that the proposed electrode could be efficiently used for the determination of GMP in the artificial samples.

The practical application of the proposed method was further proved by the measurement of GMP content in

Table 2. Determination results of GMP in artificial samples $(n=6)$

\begin{tabular}{ccccccc}
\hline Sample & $c / \mu \mathrm{mol} \mathrm{dm}^{-3}$ & $c$ (Found $) / \mu \mathrm{mol} \mathrm{dm}^{-3}$ & $c$ (Added $) / \mu \mathrm{mol} \mathrm{dm}^{-3}$ & $c$ (Total) $/ \mu \mathrm{mol} \mathrm{dm}{ }^{-3}$ & $\mathrm{RSD} / \%$ & Recovery $/ \%$ \\
\hline $1^{\text {(a) }}$ & 20.0 & 21.3 & 80.0 & 100.8 & 0.80 & 99.4 \\
$2^{\text {(b) }}$ & 40.0 & 40.5 & 60.0 & 101.4 & 1.40 & 101.5 \\
$3^{\text {(c) }}$ & 60.0 & 61.1 & 40.0 & 98.8 & 1.20 & 94.25 \\
\hline
\end{tabular}

(a) Sample 1 contains $10.0 \mu \mathrm{mol} \mathrm{dm}{ }^{-3}$ of glycin, L-leucine, $\mathrm{Cu}^{2+}, \mathrm{Zn}^{2+}$ and $20.0 \mu \mathrm{mol} \mathrm{dm}{ }^{-3} \mathrm{GTP}$.

(b) Sample 2 contains $10.0 \mu \mathrm{mol} \mathrm{dm}{ }^{-3}$ of glycin, L-leucine, $\mathrm{Zn}^{2+}, \mathrm{Na}^{+}$and $40.0 \mu \mathrm{mol} \mathrm{dm}{ }^{-3} \mathrm{GTP}$.

(c) Sample 3 contains $10.0 \mu \mathrm{mol} \mathrm{dm}{ }^{-3}$ of glycin, L-leucine, $\mathrm{Cu}^{2+}, \mathrm{Na}^{+}$and $60.0 \mu \mathrm{mol} \mathrm{dm}{ }^{-3} \mathrm{GTP}$.

Table 3. Determination results of GMP in chicken powder samples $(n=6)$

\begin{tabular}{cccccc}
\hline Sample & $c$ (Determined $) / \mu \mathrm{mol} \mathrm{dm}^{-3}$ & $c$ (Added $) / \mu \mathrm{mol} \mathrm{dm}^{-3}$ & $c($ Found $) / \mu \mathrm{mol} \mathrm{dm}{ }^{-3}$ & $\mathrm{RSD} / \%$ & Recovery $/ \%$ \\
\hline 1 & 1.425 & 1.00 & 2.406 & 1.50 & 98.1 \\
2 & 1.404 & 1.00 & 2.361 & 0.83 & 95.7 \\
3 & 1.512 & 1.00 & 2.524 & 1.20 & 101.2 \\
\hline
\end{tabular}


chicken powder samples, which were purchased from the local supermarket. The samples were treated with the following procedure. $8.0 \mathrm{~g}$ of chicken powder was dissolved in $40 \mathrm{~mL}$ water by ultrasonicated and the solution was filtrated with $0.45 \mu \mathrm{m}$ Nylon film. The filtrate was collected and diluted to $50 \mathrm{~mL}$ with double distilled water and further detected by the proposed method. All the solutions were determined for six times by the standard addition method with the results summarized in Table 3. It can be seen that the recovery was in the range from $95.7 \%$ to $101.2 \%$, indicating the precise of the proposed method.

\section{CONCLUSION}

A new IL-CPE fabricated with 1-octyl-3-methylimidazolium hexfluorophosphate (OMIMPF ${ }_{6}$ ) was developed, which exhibited the characteristics such as good stability and electrocatalytic activity. The electrooxidation of GMP was investigated with an enhanced oxidation response appeared at $1.14 \mathrm{~V}$ and electrochemical reaction was an adsorption-controlled irreversible process with two-electron and two-proton process. Under the optimized conditions good linearity was observed between the oxidation peak current and the concentration of GMP in the range from 1.0 to 1000.0 $\mu \mathrm{mol} \mathrm{dm}{ }^{-3}$ with a detection limit of $0.16 \mu \mathrm{mol} \mathrm{dm}{ }^{-3}(\mathrm{~S} / \mathrm{N}$ $=3$ ) after accumulation for $60 \mathrm{~s}$. The proposed method showed good selectivity in the detection of GMP without interference from coexisting substances and was further applied to the determination of different samples with satisfactory results.

Acknowledgements. We are grateful to the financial support of the Natural Science Foundation of China (No. 50976043), the Foundation of State Key Laboratory of Coal Combustion of Huazhong University of Science and Technology (FSKLCC1010) and the Foundation of State Key Laboratory of Clean Energy Utilization of Zhejiang University.

\section{REFERENCES}

1. J. Rothblatt, P. Novick, and T. H. Stevens (Eds.), Guidebook to the Secretory Pathway, Oxford University Press, Oxford, 1994, p. 159.

2. H. A. Harper, Review of Physiological Chemistry, Lange Medical Publications, Los Altos, CA, 1967, p. 406.

3. J. D. Carver and W. W. Allan, J. Nutr. Biochem. 6 (1995) 58-72.

4. R. Ciccarelli, P. Ballerini, G. Sabatino, M. P. Rathbone, M.
D'Onofrio, F. Caciagli, and P. Di Iorio, Int. J. Dev. Neurosci. 19 (2001) 395-414.

5. M. P. Rathbone, P. J. Middlemiss, J. W. Gysbergs, C. Andrew, M. A. R. Herman, J. K. Reed, R. Ciccarelli, P. D. Iorio, and F. Caciagli, Prog. Neurobiol. 59 (1999) 663-690.

6. M. E. Frizzo, D. R. Lara, A. S. Prokopiuk, C. R. Vargas, C. G. Salbego, M. Wajner, and D. O. Souza, Cell Mol. Neurobiol. 22 (2002) 353-363.

7. M. E. Frizzo, D. R. Lara, K. C. Dahm, A. S. Prokopiuk, R. A. Swanson, and D. O. Souza, Neuro. Report 12 (2001) 879-881.

8. M. E. Frizzo, F. A. Soares, L. P. Dall'Onder, D. R. Lara, R. A. Swanson, and D. O. Souza, Brain. Res. 972 (2003) 84-89.

9. L. Li, J. H. Yang, X. Wu, C. X. Sun, Y. Liu, S. F. Liu, and B. Y. Su, J Lumin. 109 (2004) 31-37.

10. D. Huang, Y. Zhang, and X. Chen, J. Chromatogr. 784 (2003) 101-109.

11. S. Giannattasio, S. Gagliardi, M. Samaja, and E. Marra, Brain Res. Protocols. 10 (2003) 168-174.

12. H. W. Liu, S. Z. Qi, Y. N. Zhang, A. J. Huang, and Y. L. Sun, J. High Res. Chromatogr. 20 (1997) 242-244.

13. R. N. Goyal, B. K. Puri, and N. Jain, J. Chem. Soc. Perkin Trans. 2 (2001)832-837.

14. L. Cui, L. F. Li, S. Y. Ai, H. S. Yin, P. Ju, and T. Liu, J. Solid State Electrochem. 6 (2011), 1253-1261.

15. R. N. Goyal and A. Tyagi, Anal. Bioanal. Chem. 382 (2005) 1683-1690.

16. H. Xie, D. W. Yang, A. Heller, and Z. Q. Gao, Biophys. J. 92 (2007) 70-72.

17. M. Opallo and A. Lesniewski, J. Electroanal. Chem. 656 (2011) $2-16$.

18. M. J. A. Shiddiky and A. A. J. Torriero, Biosens. Bioelectron. 26 (2011) 1775-1787.

19. D. Wei and A. Ivaska, Anal. Chim. Acta 607 (2008) 126-135.

20. H. Ohno, Electrochemical Aspects of Ionic Liquids, John Wiley \& Sons, Inc. Hoboken, New Jersey, 2005.

21. H. T. Liu, Y. Liu, and J. H. Li, Phys. Chem. Chem. Phys. 12 (2010) 1685-1697.

22. N. Maleki, A. Safavi, and F. Tajabadi, Anal. Chem. 78 (2006) 3820-3826.

23. Y. Zhang and J. B. Zheng, Talanta 77 (2008) 325-330.

24. W. Sun, R. F. Gao, and K. Jiao, J. Phys. Chem. B 111 (2007) 4560-4567.

25. W. Sun, Y. Z. Li, M. X. Yang, S. F. Liu, and K. Jiao, Electrochem. Commun. 10 (2008) 298-301.

26. W. Sun, Y. Z. Li, H. W. Gao, and K. Jiao, Microchim. Acta 165 (2009) 313-317.

27. W. Sun, Y. Z. Li, M. X. Yang, and K. Jiao, Sens. Actuators B Chem. 133 (2008) 387-392.

28. W. Sun, Q. Jiang, M. Y. Xi, and K. Jiao, Microchim. Acta 166 (2009) 343-348.

29. Y. Y. She, Y. G. Tang, H. G. Liu, and P. He, Chem. Cent. J. 4 (2010) 17-24.

30. M. D. Anjo, M. Kahr, M. M. Khodabakhsh, S. Nowinski, and M. Wagner, Anal. Chem. 61 (1989) 2603-2608.

31. E. Laviron, J. Electroanal. Chem. 100 (1979) 263-270.

32. E. E. Ferapontova, Electrochim. Acta 49 (2004) 1751-1759. 